\title{
Small Signal Model for VSC-HVDC Connected DFIG-Based Offshore Wind Farms
}

\author{
Kai Liao, Zheng-you He, and Bin Sun \\ School of Electrical Engineering, Southwest Jiaotong University, Chengdu 610031, China \\ Correspondence should be addressed to Kai Liao; liaokai.lk@foxmail.com
}

Received 26 February 2014; Revised 2 June 2014; Accepted 9 June 2014; Published 8 July 2014

Academic Editor: Jin Liang

Copyright (C) 2014 Kai Liao et al. This is an open access article distributed under the Creative Commons Attribution License, which permits unrestricted use, distribution, and reproduction in any medium, provided the original work is properly cited.

Large-scale offshore wind farms are integrated with onshore ac grids through the voltage source converter based high voltage direct current (VSC-HVDC) transmission system. The impact on the stability of the ac grids will be significant. The small signal model of a wind farm connected with voltage source converter based dc transmission system is studied in this paper. A suitable model for small signal stability analysis is presented. The control system of wind generator and the HVDC system has also been modeled in this model for small signal stability analysis. The impact of the control parameters on the network stability is investigated.

\section{Introduction}

Due to the advantages in speed control, and four-quadrant active and reactive power regular capabilities, the large offshore wind farms based on doubly fed induction generator (DFIG) have been planned around worldwide [1,2]. With the anticipated high level penetration of offshore wind power increasing, voltage source converter based high voltage direct current (VSC-HVDC) connections are expected for wind power integration with the onshore ac grids [3]. The VSCHVDC transmission is emerging as the prospective technology to address the challenges associated with the integration of future offshore wind power [4].

VSC-HVDC transmission system was employed in [5] for transmitting offshore wind power equipped with fixed speed generators to the grid. In [6,7], a $6 \mathrm{MW}$ wind farm connected to the grid through the VSC-HVDC transmission system is studied. In the future, many large wind farms under development will employ DFIG-based wind turbines whose operation and response to network disturbances are significantly different from other types of generators. The control strategy of VSC-HVDC transmission system technology for connecting large DFIG-based wind farms over long distance is studied in [8]. New control strategies for normal and grid fault conditions are proposed. To obtain smooth operation, the wind farm side converter is controlled as an infinite voltage source that automatically absorbs power generated by the wind farm and maintains a stable local ac network. In [9], line commutated HVDC systems had also been used to connect a large DFIG-based offshore wind farm into the grid.

The dynamic behavior of the DFIG has been investigated by many researchers $[10,11]$. The majority of these studies are based on time-domain simulation results to investigate the impact on power system dynamic behavior. The control method made DFIG behave like a synchronous generator [12-15]. Time-domain studies offer a direct appreciation of the dynamic behavior in terms of visual clarity. However, the time-domain simulation is hard to observe for all the oscillation modals of the systems [16]. In [17], a suitable model for small signal stability analysis and control design of multiterminal dc networks is presented. A typical test network that combines conventional synchronous and offshore fixed speed wind generation connected to onshore via a dc network is used to illustrate the design of enhanced voltage source converter controllers. The impact of VSC control parameters on network dynamic behavior is discussed.

In this paper, the DFIG-based wind farm via VSC-HVDC transmission system connected to the grid is studied. The single-machine infinite-bus (SMIB) structure is followed. The paper is organized as follows. In Section 2, the mathematical model of the system unit is observed. In Section 3, modal analysis method and the eigenvalues under employed controller parameters are studied. Section 4 presents the conclusion. 


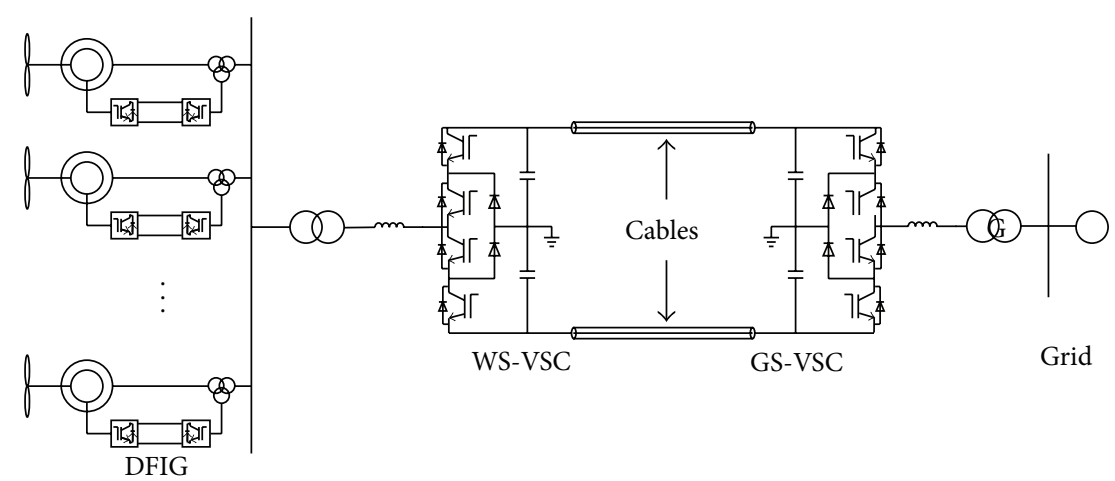

FIGURE 1: The study system.

\section{Modeling of Study System}

The study system is shown in Figure 1, where a DFIG-based wind farm (100 MW form aggregation of $2 \mathrm{MW}$ units) is connected to a VSC-HVDC link. The dc transmission voltage is $300 \mathrm{kV}$ pole-to-pole ( $\pm 150 \mathrm{kV}$-bipolar). The length of the $\mathrm{dc}$ transmission cables is $50 \mathrm{~km}$. The onshore ac power grid, which is comprised of conventional generation, is modeled as a synchronous generator with the ratings of $33 \mathrm{kV}$ and 2400 MVA.

2.1. Doubly Fed Induction Generator. The one-phase equivalent electric circuit of the DFIG rotor and stator is shown in Figure 2. The dynamic equations of DFIG are usually described by transforming the machine " $a b c$ " voltage equations into a synchronously rotating frame referred to as the " $d-q$ " frame.

For stability analysis, the generators are modeled as an equivalent voltage source based on transient impedance. The dynamic model of DFIG is shown as

$$
\begin{aligned}
\frac{d i_{q s}}{d t}= & -\frac{\omega_{e l} R_{1}}{\omega_{s} L_{s}} i_{q s}+\omega_{e l} i_{d s}+\frac{\omega_{e l} w_{r}}{\omega_{s}^{2} L_{s}} e_{q s}^{\prime}-\frac{\omega_{e l}}{T_{r} \omega_{s}^{2} L_{s}} e_{d s}^{\prime} \\
& -\frac{\omega_{e l}}{\omega_{s} L_{s}} v_{q s}+\frac{K_{m r r} \omega_{e l}}{\omega_{s} L_{s}} v_{q r}, \\
\frac{d i_{d s}}{d t}= & -w_{e l} i_{q s}-\frac{w_{e l} R_{1}}{w_{s} L_{s}} i_{d s}+\frac{w_{e l} w_{r}}{w_{s}^{2} L_{s}} e_{d s}^{\prime}-\frac{w_{e l}}{T_{r} w_{s}^{2} L_{s}} e_{q s}^{\prime} \\
& -\frac{w_{e l}}{w_{s} L_{s}} v_{d s}+\frac{K_{m r r} w_{e l}}{w_{s} L_{s}} v_{d r}, \\
\frac{d e_{q s}^{\prime}}{d t}= & w_{e l} R_{2} i_{d s}-\frac{w_{e l}}{T_{r} w_{s}} e_{q s}^{\prime}+w_{e l}\left(\frac{w_{s}-w_{r}}{w_{s}}\right) e_{d s}^{\prime} \\
& -K_{m r r} w_{e l} v_{d r}, \\
\frac{d e_{d s}^{\prime}}{d t}= & -w_{e l} R_{2} i_{d s}-\frac{w_{e l}}{T_{r} w_{s}} e_{d s}^{\prime}+w_{e l}\left(\frac{w_{r}-w_{s}}{w_{s}}\right) e_{q s}^{\prime} \\
& +K_{m r r} w_{e l} v_{q r},
\end{aligned}
$$

where $e_{q s}^{\prime}$ and $e_{d s}^{\prime}$ are the equivalent internal $q$ - and $d$-axis voltages, respectively. $i_{d s}$ and $i_{q s}$ are the stator $q$ - and $d$-axis currents, respectively. The mean of the parameters can be calculated according to [16].

2.2. Controller of DFIG Converters. The purpose of the rotor side converter controller is to control the active power so as to track the maxim power $P_{\text {ref }}$ and to maintain the terminal voltage $U_{\text {sref }}$ as a constant. For the grid-side converter, the controller has to keep the dc-link voltage as a constant and the desired sharing of reactive power with stator is achieved. Usually, the reactive power delivered to the grid is only produced from the stator to minimize the converter capacity. So, the rotor side converter works at unity power factor. According to [18], the model of rotor-side convert and its controller is shown in

$$
\begin{gathered}
\frac{d x_{1}}{d t}=P_{\mathrm{ref}}-P_{s}, \\
i_{q r \mathrm{ref}}=k_{p 1}\left(P_{\mathrm{ref}}-P_{s}\right)+k_{i 1} x_{1}, \\
\frac{d x_{i q r}}{d t}=i_{q r \mathrm{ref}}-i_{q r}, \\
\frac{d x_{2}}{d t}=U_{\mathrm{ref}}-U_{s}, \\
i_{d r \mathrm{ref}}=k_{p 3}\left(U_{\mathrm{ref}}-U_{s}\right)+k_{i 3} x_{2}, \\
\frac{d x_{i d r}}{d t}=i_{d r \mathrm{ref}}-i_{d r}, \\
\Delta v_{q r}=k_{p 2}\left(k_{p 1}\left(P_{\mathrm{ref}}-P_{s}\right)+k_{i 1} x_{1}-i_{q r}\right)+k_{i 2} x_{i q r} \\
+s_{r} \omega_{s} L_{m} i_{d s}+s_{r} \omega_{s} L_{r r} i_{q r}, \\
k_{p 2}\left(k_{p 3}\left(U_{\text {ref }}-U_{s}\right)+k_{i 3} x_{2}-i_{d r}\right)-k_{i 2} x_{i d r} \\
-s_{r} \omega_{s} L_{m} i_{q s}-s_{r} \omega_{s} L_{r r} i_{d r}, \\
\frac{d x_{3}}{d t}=U_{\mathrm{dcref}}-U_{\mathrm{dc}}, \\
i_{d g r e f}=k_{p 4}\left(U_{\mathrm{dcref}}-U_{\mathrm{dc}}\right)+k_{i 4} x_{3},
\end{gathered}
$$




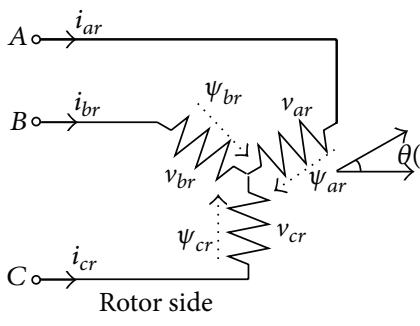

(a) The circuit of rotor and stator

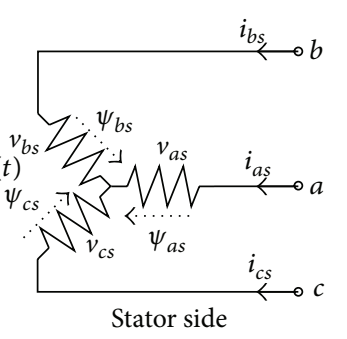

Stator side

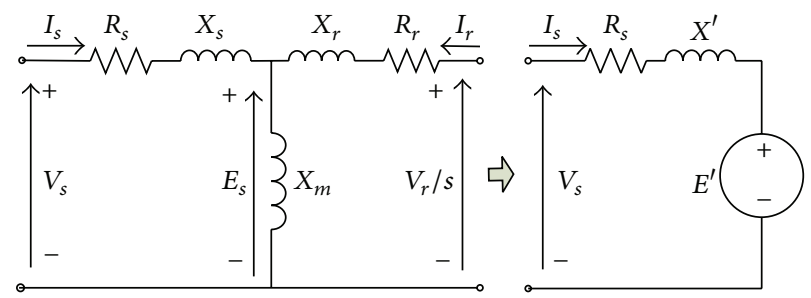

(b) Equivalent circuit

Figure 2: The equivalent electric circuit of the DFIG.

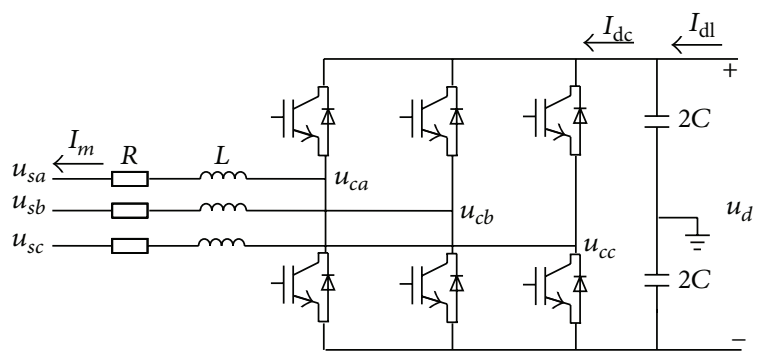

Figure 3: Converter circuit diagram.

$$
\begin{gathered}
\frac{d x_{i q g}}{d t}=i_{d g r e f}-i_{d g}, \\
\frac{d x_{i q g}}{d t}=i_{q g r e f}-i_{q g}, \\
\Delta v_{d g}=k_{p 5}\left(-k_{p 4}\left(U_{\text {dcref }}-U_{\text {dc }}\right)+k_{i 4} x_{3}-i_{d g}\right)+k_{i 5} x_{i q g}, \\
\Delta v_{q g}=k_{p 6}\left(i_{q g r e f}-i_{q g}\right)+k_{i 6} x_{i q g} .
\end{gathered}
$$

2.3. VSC-HVDC System Converter. The VSC-HVDC system is employed to transfer wind energy from offshore to onshore. As shown in Figure 1, the key unit of the HVDC system is the converter. The wind farm side converter is to transfer the energy received from wind turbine. The grid side converter is to keep the DC voltage as a constant value in order. Figure 3 illustrated a VSC-HVDC converter circuit diagram in " $a b c$ " frame.

As shown in Figure 3, it is easy to show the dynamic model of the converter in " $a b c$ " frame

$$
\left[\begin{array}{l}
u_{c a} \\
u_{c b} \\
u_{c c}
\end{array}\right]=L \frac{d}{d t}\left[\begin{array}{l}
i_{a} \\
i_{b} \\
i_{c}
\end{array}\right]+R\left[\begin{array}{l}
i_{a} \\
i_{b} \\
i_{c}
\end{array}\right]+\left[\begin{array}{l}
u_{s a} \\
u_{s b} \\
u_{s c}
\end{array}\right] .
$$

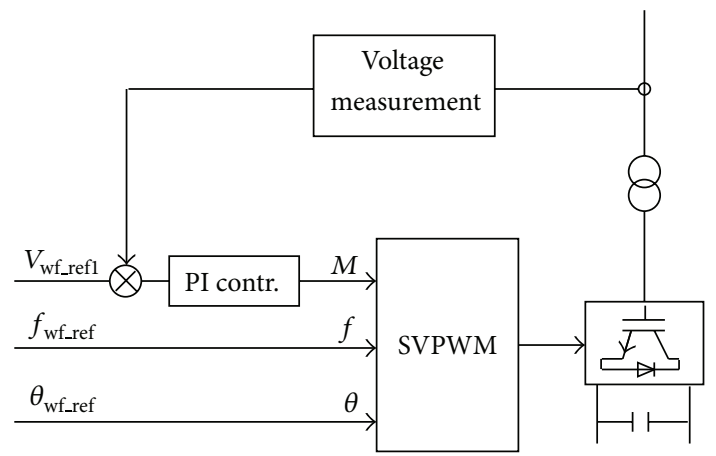

Figure 4: Control block diagram of the wind farm side converter.

The dynamic model in " $d-q$ " frame can be easy obtained by employing the Park transform as shown in (4), and the " $d-q$ " frame dynamic model is shown in (5):

$$
\begin{aligned}
& P=\frac{2}{3}\left[\begin{array}{lll}
\sin w t & \sin \left(w t-120^{\circ}\right) & \sin \left(w t+120^{\circ}\right) \\
\cos w t & \cos \left(w t-120^{\circ}\right) & \cos \left(w t+120^{\circ}\right)
\end{array}\right], \\
& \frac{d}{d t}\left[\begin{array}{l}
i_{m d} \\
i_{m q}
\end{array}\right]=\frac{1}{L}\left[\begin{array}{l}
v_{c d} \\
v_{c q}
\end{array}\right]-\frac{R}{L}\left[\begin{array}{l}
i_{m d} \\
i_{m q}
\end{array}\right]-\frac{1}{L}\left[\begin{array}{l}
u_{s d} \\
u_{s q}
\end{array}\right] \\
& -\left[\begin{array}{cc}
0 & -\omega \\
\omega & 0
\end{array}\right]\left[\begin{array}{c}
i_{m d} \\
i_{m q}
\end{array}\right] \text {, }
\end{aligned}
$$

where $c$ means the converter side parameters and $s$ means the grid side parameters. Under PWM control, the amplitude of the converter output fundamental voltage is controlled by the modulation index $M$ as

$$
V_{c}=\frac{M \cdot V_{\mathrm{dc}}}{2} .
$$

In ideal condition, the dynamic of the dc side transmission system is shown in

$$
\frac{d V_{\mathrm{dc}}}{d t}=\frac{1}{C} \cdot I_{\mathrm{dc}}-\frac{3}{4 C}\left(M_{d} \cdot i_{m d}+M_{q} \cdot i_{m q}\right),
$$

where the $i_{m d}$ and $i_{m q}$ are the $d$ - and $q$ - axis converter currents, respectively. $M$ is the modulation index. $V_{\mathrm{dc}}$ is the DC voltage and $I_{\mathrm{dc}}$ is the DC current.

2.4. Controller of Wind Farm Side Converter. The wind farm side converter (WFVSC) should keep the wind farm side 


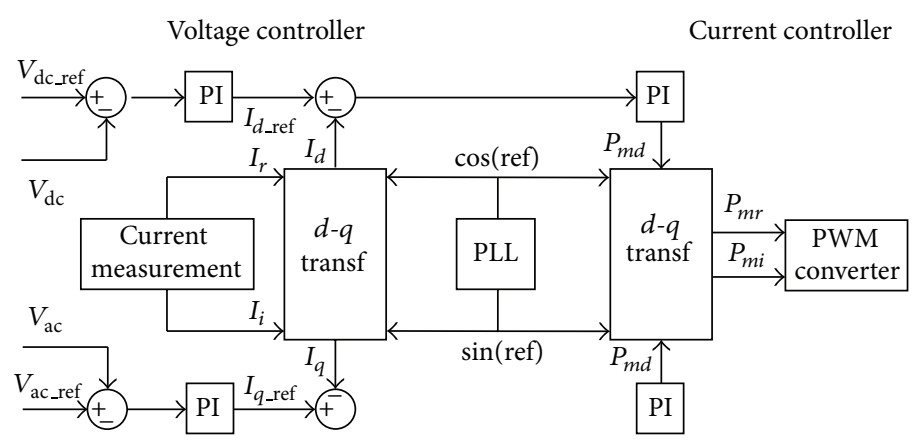

FIGURE 5: Control block diagram of the grid side converter.

ac bus working at constant frequency and voltage. So, the controller of wind farm side converter should maintain the ac bus frequency and voltage as a constant. After that, the primary requirement of the WFVSC is to transfer energy collected from the wind farm. The output power form DFIG is controlled by power electronic converters and MPPT system and the network frequency variations when little influence is on the power generation. The main task for the WFVSC is to collect energy from the wind farm and to control the ac voltage and frequency of the local wind farm network. Therefore, the control strategy adopted on the WFVSC is to control the wind farm side converter as an infinite voltage source with constant frequency, voltage amplitude, and phase angle. The control block diagram for the WFVSC is shown in Figure 4.

Consider the voltage measurement devise delay; the measurement unit can be modeled as a first-order process,

$$
V_{\text {mea }}=V_{w f} \cdot \frac{1}{1+T s},
$$

as

$$
\frac{d V_{\text {mea }}}{d t}=\frac{V_{w f}-V_{\text {mea }}}{T} .
$$

The controller of the converter is respected to the bus voltage as shown in Figure 4. The dynamic model of the wind farm side converter controller is shown as

$$
\frac{d M}{d t}=-K_{p 7}\left(\frac{V_{w f}-V_{\text {mea }}}{T}\right)+K_{i 7} V_{w f \_ \text {ref } 1}-K_{i 7} V_{\text {mea }} .
$$

Thus, the control strategy makes the wind farm be connected to an infinite ac system; the power generated by the wind farm is automatically absorbed by the source resembled by the wind farm side converters and then transmitted to the grid via the DC lines.

2.5. Controller of Grid Side HVDC Converter. The WSVSC collects energy from wind farm and then transmits it to the power grid via the dc transmission and grid side converter (GSVSC) (Figure 5). For a dc transmission system, we expect the $\mathrm{dc}$ voltage to maintain a constant value under all condition to keep the system work stability. A constant dc voltage indicates balanced active power flow between the two

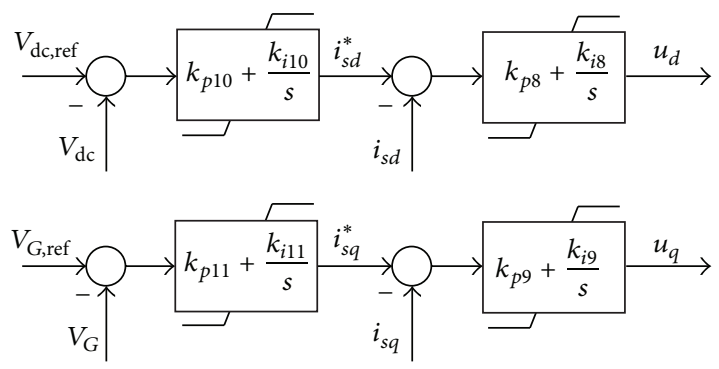

FIgURE 6: The control system of the grid side converter.

sides. Unstable dc link voltage can cause the system to trip and disrupt its normal operation. Therefore, the grid side converter is assigned to control the dc voltage as the expected value. The PI control system of the grid side converter is shown in Figure 6. The control method can ensure the energy collected by the wind farm is transmitted to the grid network almost completely. The reference angle for $a b c-d q$ transfer is obtained from the PLL loop.

The current control loop is designed as

$$
\begin{aligned}
& u_{d}=\frac{d i_{s d}}{d t}=k_{p 8}\left(i_{s d}^{*}-i_{s d}\right)+k_{i 8} \int\left(i_{s d}^{*}-i_{s d}\right) d t, \\
& u_{q}=\frac{d i_{s q}}{d t}=k_{p 9}\left(i_{s q}^{*}-i_{s q}\right)+k_{i 9} \int\left(i_{s q}^{*}-i_{s q}\right) d t,
\end{aligned}
$$

where $i_{s d}^{*}$ is the dc voltage control loop and $i_{s q}^{*}$ is the connection bus voltage control loop:

$$
\begin{aligned}
& i_{s d}^{*}=k_{p 10}\left(V_{\mathrm{dc}}^{*}-V_{\mathrm{dc}}\right)+k_{i 10} \int\left(V_{\mathrm{dc}}^{*}-V_{\mathrm{dc}}\right) d t \\
& i_{s q}^{*}=k_{p 11}\left(V_{G}^{*}-V_{G}\right)+k_{i 11} \int\left(V_{G}^{*}-V_{G}\right) d t .
\end{aligned}
$$

The VSC control modulation index $M$ in $d q$ frame is shown in

$$
\begin{aligned}
& M_{d}=\frac{2 L}{V_{\mathrm{dc}}}\left(u_{d}+\frac{R}{L} i_{s d}-\omega_{s} i_{s q}+\frac{1}{L} v_{s d}\right), \\
& M_{q}=\frac{2 L}{V_{\mathrm{dc}}}\left(u_{q}+\frac{R}{L} i_{s q}+\omega_{s} i_{s d}+\frac{1}{L} v_{s q}\right) .
\end{aligned}
$$




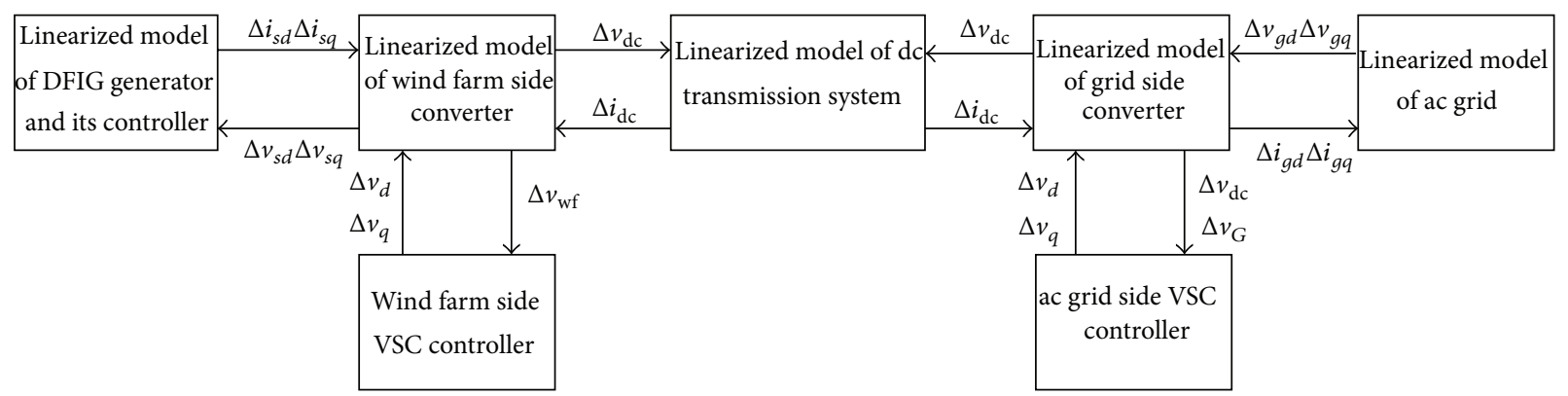

FIGURE 7: The combined small signal model for whole system.

TABLE 1: Controller parameters.

\begin{tabular}{lcccccccccc}
\hline$k_{p 1}$ & $k_{p 2}$ & $k_{p 3}$ & $k_{p 4}$ & $k_{p 5}$ & $k_{p 6}$ & $k_{p 7}$ & $k_{p 8}$ & $k_{p 9}$ & $k_{p 10}$ & $k_{p 11}$ \\
\hline 0.45 & 0.5 & 0.025 & 0.005 & 0.01 & 0.25 & 15 & 1 & 1 & 10 & 0.01 \\
\hline$k_{i 1}$ & $k_{i 2}$ & $k_{i 3}$ & $k_{i 4}$ & $k_{i 5}$ & $k_{i 6}$ & $k_{i 7}$ & $k_{i 8}$ & $k_{i 9}$ & $k_{i 10}$ & $k_{i 11}$ \\
\hline 0.25 & 0.45 & 0.2 & 0.15 & 0.25 & 0.15 & 20 & 8 & 8 & 200 & 300 \\
\hline
\end{tabular}

For small signal model, four middle variables named $x_{v \mathrm{dc}}, \quad x_{i s d}, \quad x_{v g}$, and $x_{i s q}$ are employed: $x_{v \mathrm{dc}}=\int\left(V_{\mathrm{dc}}^{*}-V_{\mathrm{dc}}\right)$, $x_{i s d}=\int\left(i_{s d}^{*}-i_{s d}\right), x_{v g}=\int\left(V_{G}^{*}-V_{G}\right)$, and $x_{i s q}=\int\left(i_{s q}^{*}-i_{s q}\right)$.

Combine (11) with (13) and the middle variables; the dynamic model for GSVSC can be obtained as shown in

$$
\begin{gathered}
\frac{d x_{v \mathrm{dc}}}{d t}=V_{\mathrm{dc}}^{*}-V_{\mathrm{dc}}, \\
\frac{d x_{i s d}}{d t}=k_{p 10}\left(V_{\mathrm{dc}}^{*}-V_{\mathrm{dc}}\right)+k_{i 10} x_{v \mathrm{dc}}-i_{s d}, \\
\frac{d x_{v g}}{d t}=V_{G}^{*}-V_{G}, \\
\frac{d x_{i s q}}{d t}=k_{p 11}\left(V_{G}^{*}-V_{G}\right)+k_{i 11} x_{v g}-i_{s q}, \\
V_{g c d}=-k_{p 8} k_{p 10}\left(V_{\mathrm{dc}}^{*}-V_{\mathrm{dc}}\right)+k_{p 8} k_{i 10} x_{v \mathrm{dc}} \\
-k_{p 8} i_{s d}+k_{i 8} x_{i s d}, \\
V_{g c q}=k_{p 9} k_{p 11}\left(V_{G}^{*}-V_{G}\right)+k_{p 9} k_{i 11} x_{v g} \\
-k_{p 9} i_{s q}+k_{i 11} x_{i s q} .
\end{gathered}
$$

\section{Modal Analysis}

The complete state-space representation of the test system is obtained by combining all the linearized models. As shown in Figure 7 the small signal model of the whole system is combined.

The small signal stability can be observed by eigenvalue analysis of the whole system linearized model. In this case, the "small signal" disturbances are considered sufficiently small to permit the equations representing the system to be linearized and expressed in state-space form. The model of a power system can be expressed as a set of DAE. The linearized
TABLE 2: Eigenvalues.

\begin{tabular}{lccc}
\hline$\lambda$ & Value & $f(\mathrm{~Hz})$ & Damping ratio \\
\hline$\lambda_{1,2}$ & $-1428 \pm j 7654$ & 1218.7 & 0.183 \\
$\lambda_{3,4}$ & $-316 \pm j 1468$ & 215.8 & 0.21 \\
$\lambda_{5,6}$ & $-14.89 \pm j 283$ & 45.06 & 0.053 \\
$\lambda_{7,8}$ & $-5.6 \pm j 212$ & 33.76 & 0.026 \\
$\lambda_{9,10}$ & $-45.1 \pm j 521$ & 82.96 & 0.086 \\
$\lambda_{11,12}$ & $-7.8 \pm j 85.3$ & 13.58 & 0.091 \\
$\lambda_{13,14}$ & $-28.3 \pm j 219.6$ & 34.97 & 0.128 \\
$\lambda_{15,16}$ & $-9.4 \pm j 8.21$ & 1.31 & 0.753 \\
$\lambda_{17,18}$ & $-1.8 \pm j 5.68$ & 0.9 & 0.302 \\
$\lambda_{19,20}$ & $-0.004 \pm j 4.35$ & 0.69 & 0.009
\end{tabular}

model of the test system can be expressed in state-space form as in

$$
\Delta \dot{\mathbf{x}}=\mathbf{A} \Delta \mathbf{x}+\mathbf{B} \Delta \mathbf{u}
$$

where $\Delta \mathbf{x}$ is the state vector with 26 orders, $\mathbf{u}$ is the input vector, $\mathbf{A}$ is the state matrix, and $\mathbf{B}$ is the input or control matrix. The eigenvalue of the state matrix A provides the necessary information about the small signal stability of the system.

The purpose to model the small signal model of the system is to study the small signal stability and for the further study to investigate the controller parameters design to enhance the small signal stability. The control parameters employed in this study are shown in Table 1.

The eigenvalue analysis of the small signal model is show in Table 2. Eigenvalues shown here are all the oscillation mode. It is known that the whole real part of the eigenvalues is negative and the oscillation mode is stable under the controller parameters in Table 1. 


\section{Conclusion}

A linearized mathematical model for small signal stability analysis of VSC-HVDC transmission system collected with a DFIG-based wind farm has been presented in this paper. The linearized model is based on the state-space models. The state matrix is employed to investigate the small signal stability performance of the studied system through the eigenvalue analysis. It was validated that, using the small signal stability model, it was possible to design improved controllers for the VSCs of the dc network, which ensure stable network operation and enhanced dynamic performance.

\section{Conflict of Interests}

The authors declare that there is no conflict of interests regarding the publication of this paper.

\section{Acknowledgment}

This work was supported by the National High Technology Research and Development Program (no. 2012AA050208).

\section{References}

[1] R. Pena, J. C. Clare, and G. M. Asher, "Double fed induction generator using back-to-back PWM converter and its application to variable speed wind energy generation," IEE ProceedingsElectric Power Applications, vol. 143, no. 3, pp. 231-241, 1996.

[2] T. Ackermann, "Transmission systems for offshore wind farms," IEEE Power Engineering Review, vol. 22, no. 12, pp. 23-27, 2002.

[3] D. C. Kong and X.-. Zhang, "Modelling and control of offshore wind farm with VSC-HVDC transmission system," in Proceedings of the 9th IET International Conference on AC and DC Power Transmission (ACDC '10), pp. 1-6, London, UK, October 2010.

[4] W. Lu and B. Ooi, "Optimal acquisition and aggregation of offshore wind power by multiterminal voltage-source HVDC," IEEE Transactions on Power Delivery, vol. 18, no. 1, pp. 201-206, 2003.

[5] D. Xiang, L. Ran, J. R. Bumby, P. J. Tavner, and S. Yang, "Coordinated control of an HVDC link and doubly fed induction generators in a large offshore wind farm," IEEE Transactions on Power Delivery, vol. 21, no. 1, pp. 463-471, 2006.

[6] K. H. Sobrink, P. L. Sorensen, P. Christensen, N. Sandersen, K. Eriksson, and P. Holmberg, "DC feeder for connection of a wind farm," in Proceedings of the Cigré Symposium, Kuala Lumpur, Malaysia, September 1999.

[7] X. I. Koutiva, T. D. Vrionis, N. A. Vovos, and G. B. Giannakopoulos, "Optimal integration of an offshore wind farm to a weak AC grid," IEEE Transactions on Power Delivery, vol. 21, no. 2, pp. 987-994, 2006.

[8] L. Xu, L. Yao, and C. Sasse, "Grid integration of large DFIGbased wind farms using VSC transmission," IEEE Transactions on Power Systems, vol. 22, no. 3, pp. 976-984, 2007.

[9] S. V. Bozhko, R. V. Blasco-Giménez, R. Li, J. C. Clare, and G. M. Asher, "Control of offshore DFIG-based wind farm grid with line-commutated HVDC connection," IEEE Transactions on Energy Conversion, vol. 22, no. 1, pp. 71-78, 2007.

[10] J. G. Slootweg, Wind power modelling and impact on power systems dynamics [Ph.D. dissertation], Delft University of Technology, Delft, The Netherlands, 2003.
[11] V. Akhmatov, Analysis of dynamic behaviour of electric power systems with large amount of wind power [Ph.D. dissertation], Technical University of Denmark, Lyngby, Denmark, 2003.

[12] M. V. A. Nunes, J. A. P. Lopes, H. H. Zürn, U. H. Bezerra, and R. G. Almeida, "Influence of the variable-speed wind generators in transient stability margin of the conventional generators integrated in electrical grids," IEEE Transactions on Energy Conversion, vol. 19, no. 4, pp. 692-701, 2004.

[13] F. M. Hughes, O. Anaya-Lara, N. Jenkins, and G. Strbac, "Control of DFIG-based wind generation for power network support," IEEE Transactions on Power Systems, vol. 20, no. 4, pp. 1958-1966, 2005.

[14] D. Alvira, J. Arevalo, C. Bermudez et al., "Feasibility studies of the HVDC submarine interconnection between the Spanish peninsula and the Balearic island of Mallorca," in Proceedings of the 41st International Conference on Large High Voltage Electric Systems (CIGRE '06), pp. 4-104, Paris, France, September 2006.

[15] R. S. Pena, Vector control strategies for a doubly-fed induction generator driven by a wind turbine [Ph.D. dissertation], University of Nottingham, Nottingham, UK, 1996.

[16] F. Mei and B. Pal, "Modal analysis of grid-connected doubly fed induction generators," IEEE Transactions on Energy Conversion, vol. 22, no. 3, pp. 728-736, 2007.

[17] G. O. Kalcon, G. P. Adam, O. Anaya-Lara, S. Lo, and K. Uhlen, "Small-signal stability analysis of multi-terminal VSC-based DC transmission systems," IEEE Transactions on Power Systems, vol. 27, no. 4, pp. 1818-1830, 2012.

[18] F. Wu, X.-P. Zhang, K. Godfrey, and P. Ju, "Small signal stability analysis and optimal control of a wind turbine with doubly fed induction generator," IET Generation, Transmission and Distribution, vol. 1, no. 5, pp. 751-760, 2007. 


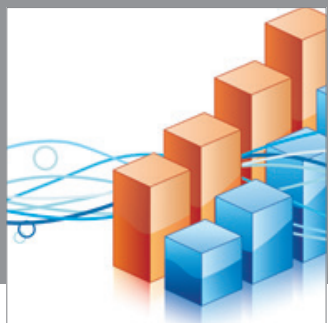

Advances in

Operations Research

mansans

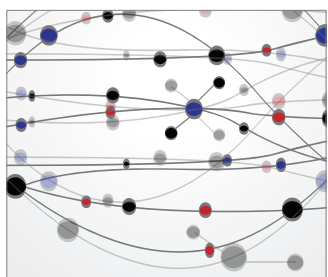

The Scientific World Journal
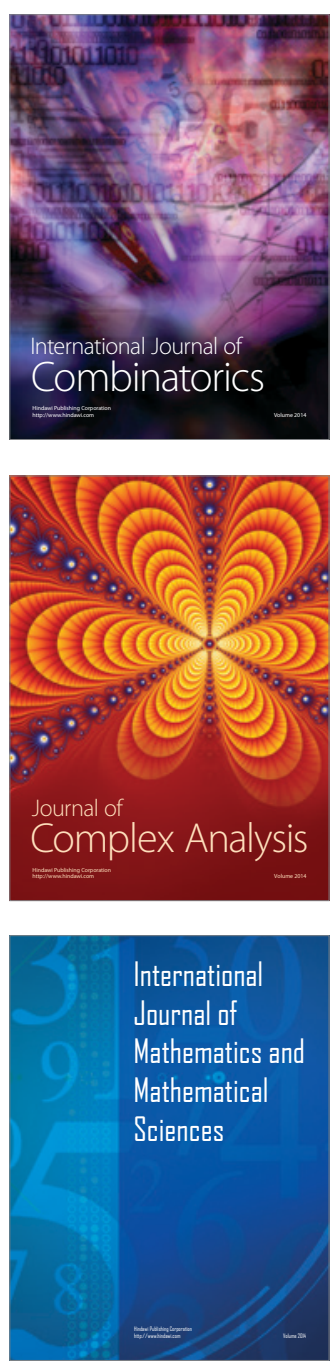
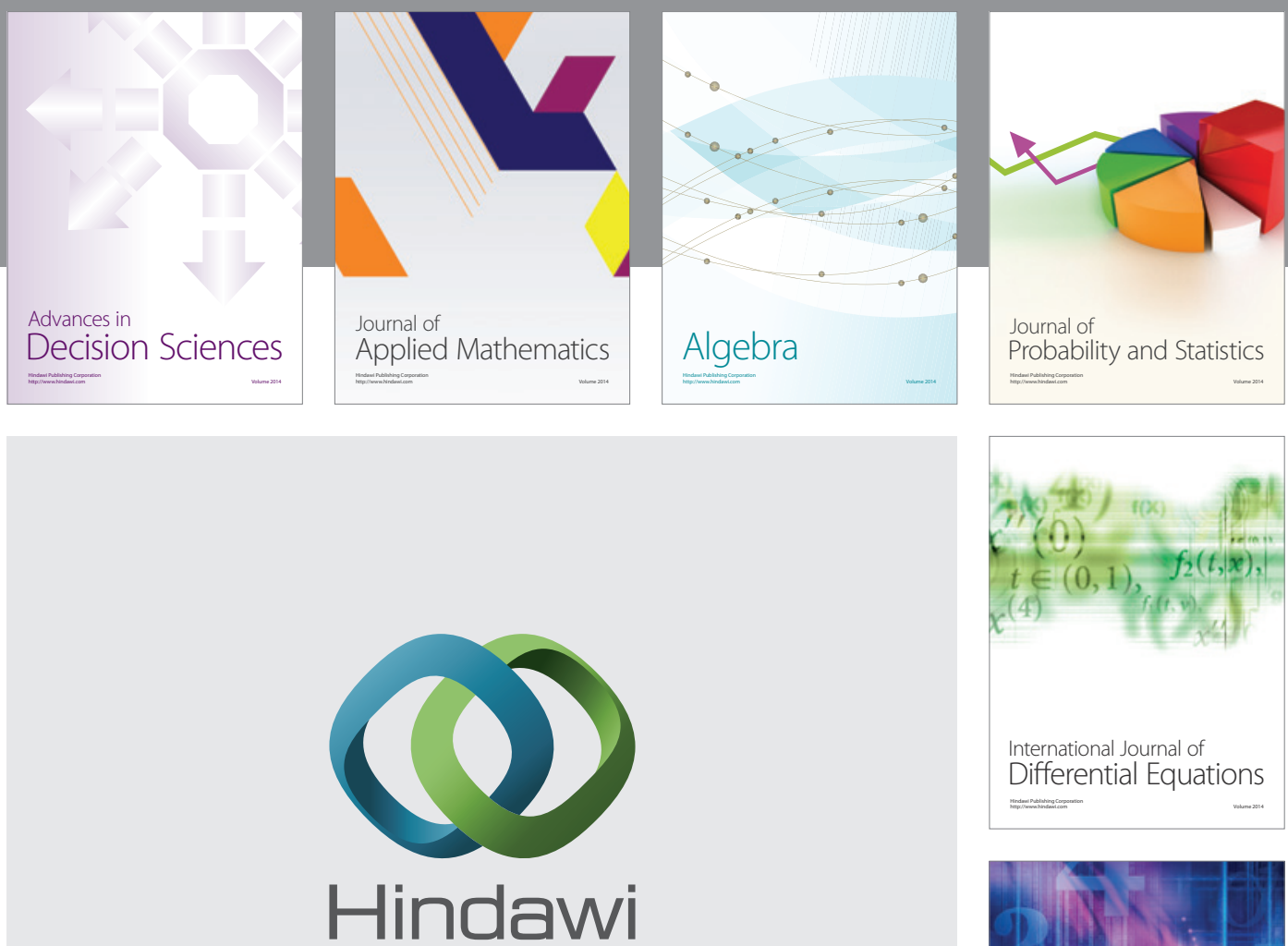

Submit your manuscripts at http://www.hindawi.com
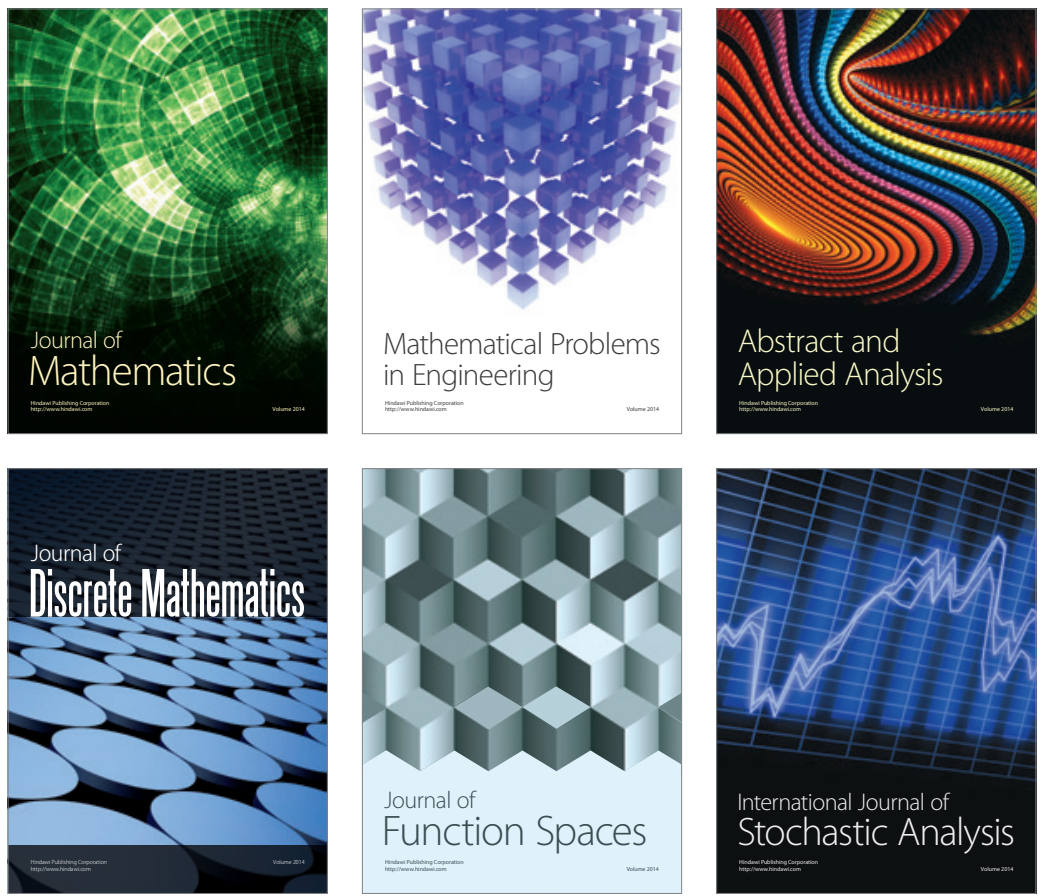

Journal of

Function Spaces

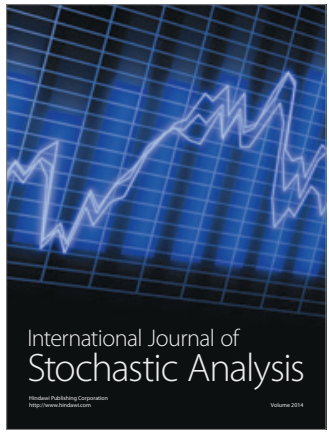

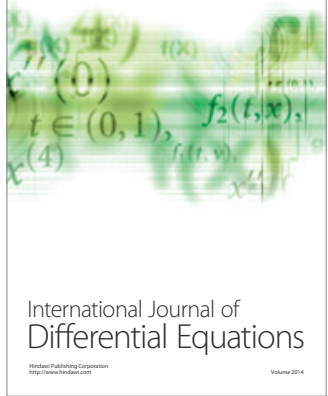
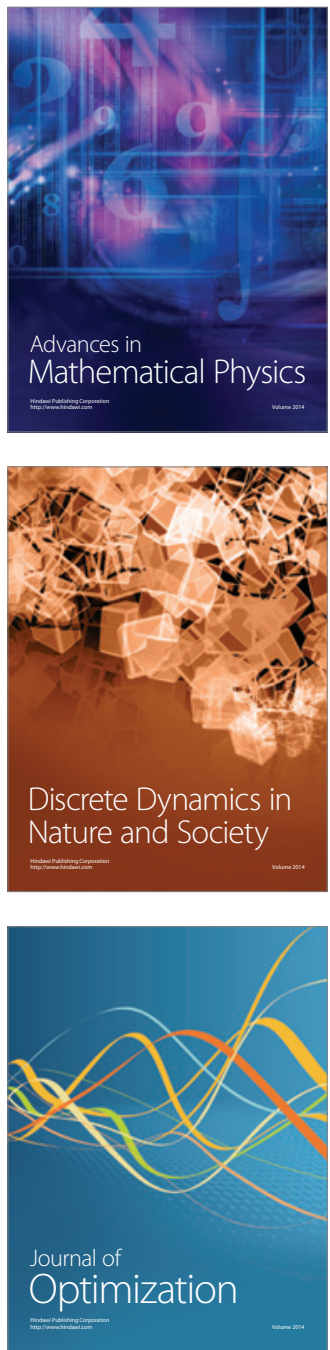